\title{
Conscripted without Induction Order: Wives of Former Combat Veterans with PTSD Speak
}

\author{
Shaul Kimhi ${ }^{1 *}$, Hadas Doron ${ }^{2}$ \\ ${ }^{1}$ Department of Psychology, Tel Hai College, Upper Galilee, Israel \\ ${ }^{2}$ Department of Social Work, Tel Hai College, Upper Galilee, Israel \\ Email: shaul@shamir.org.il, shaulkim@adm.telhai.ac.il
}

Received January $2^{\text {nd }}, 2013$; revised February $2^{\text {nd }}, 2013$; accepted February $27^{\text {th }}, 2013$

\begin{abstract}
This study examines the lives of wives who are living with former combat soldiers with chronic PTSD, from the subjective perspective of the wives themselves. Structured interviews with 20 wives indicated the following main results: 1 ) About 2/3 of the wives reported that, for a long time, they did not know what the problem with their husband was and had no idea that it was connected to his military experience. 2) All of the wives described many negative effects of their husband's situation on daily family functioning. In most cases, the wives described their husbands as handicapped individuals who could do very few things that are usually associated with normal family functioning. 3) Most wives described their husbands as "absent-present": The husband was present physically but would often detach himself from everyone around him. 4) Most wives reported suffering from anxieties of all kinds and other symptoms, which also characterized their husbands. Study results are discussed in light of relevant theories.
\end{abstract}

Keywords: PTSD; Trauma as a Result of Combat Reaction; Family Coping; Husbands PTSD Effects on Family; Secondary Traumatization; Present-Absent Relationship

Over the past 25 years, about half of all countries in the world have been affected by wars (Marshall \& Cole, 2009). War is one of the most potent traumatic experiences known to man. It often results in short-term combat stress reaction (CSR, e.g., Umbrasas, 2010) or acute stress disorder (ASD), and long-term psychopathology, most notably posttraumatic stress disorder (PTSD, American Psychiatric Association, DSMIV-TR, 2000; Magruder \& Yeager, 2009; Renshaw \& Campbell, 2011). According to researches, a substantial number of soldiers as well as their families show a wide range of symptoms long after the waris over (e.g., Everson \& Figley, 2011; Solomon, Horesh, \& Ein-Dor, 2009).

The aim of the current study is to examine several aspects of negative long-term effects of war: the lives of wives who are living with former combat soldiers suffering from chronic PTSD, from the subjective perspective of the wives themselves. Most studies that have examined the effects of PTSD have focused on the lives of the soldiers and were based on quantitative methods. Some studies have focused on the effects of this situation on families (e.g., Gold et al., 2007) and fewer studies have examined the issue from the veterans' or their wives' perspectives (e.g., Ray \& Vansone, 2009). The current phenomenological study is based on in-depth interviews with twenty women married to former combat veterans who have been affected by PTSD for many years. The purpose of this study is to give us a glance into how life looks when one's husband has chronic PTSD. The majority of relevant research has focused on wives' stress symptoms, while other issues have been studied to a much lesser extent.

\footnotetext{
${ }^{*}$ Corresponding author.
}

\section{Combat Stress Reaction and Posttraumatic Stress Disorder}

Soldiers who have been exposed to combat operations undergo massive stress. This experience can lead to immediate or delayed stress reactions that may harm psychological wellbeing, physical health and functioning in the short and the long term (Benyamini, Ein-Dor, Ginzburg \& Solomon, 2009). War-induced psychic trauma is most often expressed in either or both of two related mental disorders (Waysman et al., 1993).

The first is combat stress reaction (CSR), which is a military diagnosis but not an official DSM diagnosis. CSR refers to a breakdown on the battlefield, characterized by a wide range of acute psychological and somatic manifestations, (e.g., anxiety, withdrawal, running amok) that signify that the individual has ceased to function as a combatant (Benyamini \& Solomon, 2005). When these symptoms continue to exist for at least a month and meet the DSM criteria, a diagnosis of PTSD is applied (e.g., Cardena \& Carlson, 2011).

The second is posttraumatic stress disorder (PTSD), an official DSM IV-TR diagnosis (American Psychiatric Association, 2000). It refers to a psychiatric syndrome characterized by several symptoms that continue for at least one month: 1) recurrent re-experiencing of the traumatic event through nightmares or intrusive memories. 2) Avoidance of stimuli associated with the trauma, and emotional numbness. 3) Increased arousal including symptoms such as insomnia, inability to tolerate noise, and excessive response when startled. If most criterion are met but the time passed since the traumatic event is less than a month, a diagnosis of Acute Stress Disorder is given (Butcher, Mineka, \& Hooley, 2010). One should keep in mind that in many cases 
PTSD may be delayed and may develop long time after the traumatic experience took place (e.g., Andrews, Brewin, Stewart, Philpott, \& Hejdenberg, 2009; McFarlane, 2010; Smid, Mooren, van der Mast, Gersons, \& Kleber, 2009).

The current study focuses on wives of former combat veterans who were officially diagnosed as suffering from PTSD, either a short or a long time after their combat experiences. Inter alia, our study focuses on one important aspect that has been studied very little: the wives' experience, beginning from their husband's traumatic involvement until they recognized their husband's problem and the husband's official diagnosis.

\section{Negative Effects of the Combat Veteran Husband on Spouse and Family}

The negative effects of the husbands' traumatic experience have been studied with regard to: the entire family (Galovski \& Lyons, 2004; Gold et al., 2007; Ray \& Vanstone, 2009; Wezelman, 2011), spouses and children (Ben Arzi, Solomon, \& Dekel, 2000; Bramsen, Van der Ploeg, \& Twisk, 2002; Dekel et al., 2005; Dirkzwager, Bramsen, Ader, \& Van der Ploge, 2005; Ein-Dor, Doron, Mikulincer, Solomon, \& Shaver, 2010; Waysman, Mikulincer, Solomon, \& Weisenberg, 1993); wives of Israeli POWs (Dekel, 2007; Dekel \& Solomon, 2006); marital relationships (Solomon et al., 2011) and parenting (Cohen, Zerach, \& Solomon, 2011). These studies have indicated many negative effects of the PTSD afflicted former combat soldiers on their entire own family. The current study explores how the husband's chronic PTSD affect various aspects of family life, such as daily functioning, economic situation, social life, leisure time and couple relations over the years, from the wives point of view.

One of the negative effects of the husbands' chronic PTSD on the families which were researched more extensively is "secondary traumatization". This term has been used to indicate that people who come into close contact with a trauma victim may experience considerable emotional upset and may, over time, become indirect victims of the trauma themselves (Figley, 1983). Overall, studies have supported the concept of secondary traumatization among wives of former combat soldiers (e.g., Ben Arzi, Solomon, \& Dekel, 2000; Bramsen, van der Ploeg, \& Twisk, 2002). Yet, Renshaw et al. (2011) have demonstrated that most wives of service members/veterans with PTSD in their study experienced generic psychological distress that is not conceptually consistent with secondary traumatic stress but which reflects general psychological distress. The current study examines how the wives of former combat soldiers describe their own signs of distress or secondary traumatization.

\section{Family Coping}

In addition to distress symptoms, the current study examines wives' successful coping. Many factors affect both of these aspects (e.g., Bonanno, 2004). Studies have indicated that the family is one of the most important resources, affecting both resilient and healthy development, as well as vulnerability as a reaction to potential traumatic events (e.g., Bronfenbrenner, 2005; Hobfoll, 2001). McCubbin and his colleagues (McCubbin, Boss, Wilson, \& Lester, 1980; McCubbin \& Patterson, 1982; McCubbin et al., 1998) as well as other researchers (Berger \& Weiss, 2009; Wadsworth, 2010), when explaining variability in military families' responses to the crises of war, observed that many families moved from crises to successful adaptation and resiliency. Family resilience implies the capacity of a family to successfully manage challenging life circumstances-now or in the future (Walsh, 1998). Most scholars writing about family resiliency have focused on the relational processes within families as the primary basis for considering their resiliency (e.g., Black \& Lobo, 2008; Becvar, 2013; Walsh, 2011). In order to better understand some of these factors, the current study asked the wives what had helped them to cope with this difficult situation, through the years.

\section{Research Questions}

The current study examines four main issues regarding the effects of the husband's PTSD on his wife and family. However, beyond the general assumption that our subjects would report many difficulties in living for years with a husband suffering from PTSD, the inquiry in this study was not based on specific hypotheses. The main questions were chosen mainly due to the limited number of studies and especially the lack of phenomenological perspective on these issues. The four main questions are:

1) What was the process that wives experienced beginning from their husband's potentially traumatic experience until they recognized their husband's problem?

2) How did the husband's chronic PTSD affect various aspects of family life over the years: daily functioning, economic situation, social life, leisure time, couple relations?

3) What are the characteristics of the wives' secondary traumatization?

4) What helped the wives to cope with hardships though the years?

\section{Method}

\section{Sample}

As a first step, the authors asked a woman whom they knew as participating in meetings of a support group of wives who are living with former combat soldiers with chronic PTSD to request that these women agree to be interviewed for our study. Four wives (out of ten) agreed and then, a "snowball” samplingwas used: Each interviewed wife was asked to refer to other women she knew who were in a similar situation. Wives were instructed to call the other woman and get her permission to give the authors her phone number. This was an obligatory precondition for the authors to call the next subject and ask her to participate in the study and to be interviewed.

Five wives refused to take part in the study. The final sample consisted of 20 wives of former combat soldiers with chronic PTSD. Ages of participants ranged from 35 to $61(M=48, S D$ = 7.6). The husbands' traumatic events were from the following wars: Two from the Six Day War (1967), nine from the Yom Kippur War (1973), two from the First Lebanon War (1982), two from the Second Lebanon War (2006), and the five others during reserve duty (one in southern Lebanon in 1987). Some of the wives reported that their husband's syndrome had started immediately after the traumatic events (eight wives, 40\%) and the others $(60 \%)$ reported that there was a process of deterioration (between a few months to several years after the original traumatic event). The wives have two to four children each. Ages of children ranged from 3 to $33(M=16, S D=8.3)$. Eleven of the wives (55\%) have had a high school education, 
five have had an academic education (25\%) and four did not report on their education. According to the wives, the official percentage of disability of their husbands range from 70 to 15 ( $M=44.2, S D=15.8)$. However, five of the wives reported that their case is still pending, and two of the wives did not report this data. Ten of the husbands are unemployed and the others either work part time or work for temporary periods interspersed with unemployment.

\section{The Interview and Analysis}

The research tool was a structured interview constructed in three steps: First, based on research literature regarding secondary traumatization and wives of former combat veterans with chronic PTSD, a first draft of the interview prepared. Second, three wives living with partners who were former combat soldiers with chronic PTSD were interviewed for their comments (they were not included in the final sample). Following this, we changed questions according to their comments. Third, the last step was repeated with another two wives (included in the final sample). At the end of this step, the final version was constructed as follows: Each domain started with a general open question, followed by specific questions (only if the information in reply to the general open question was not sufficient). In this way, every interviewee was allowed to respond in her own way, with a minimum of guidance from the interviewers. Examples of the open questions: 1 ) When did you first realize that your husband was suffering from combat stress reaction? How did you discover this? What did you do with this understanding? 2) Please describe your functioning and that of your family in general during the last year. 3) Tell us about your husband's and your social life during the last three years? 4) Describe the relationship with your husband today? Have these relationships changed during the years since your husband's official diagnosis?

Content analysis of interviews was done by attributing texts to content categories (e.g., Krippendorf, 1980; Jones et al., 2010). The process of building content categories was first based on the interview's predetermined four general open questions, which served as main categories. Each main category was divided into subcategories. The process of building content categories was first based on the interview with predetermined four general open questions.

The process of attributing text to sub-categories (within each of the main four categories) was conducted as follows: The main researcher and two assistant researchers read the texts and attributed them independently to content categories. Comparison of content categories among the three researchers revealed high agreement of $84 \%$. All texts which indicated no agreements regarding their attribution to categories were brought up for further discussion, and only if no agreement was reached (less than 4\%) another independent researcher was asked to decide. Based on content analysis, the main categories and sub-categories analyzed in this study were as follows: 1) Realizing the problem: Discovery of the problem, the understanding process after the discovery. 2) Family functioning: daily functioning, economic situation, couple's social life, leisure time, couple's relations. 3) Characteristics of the wives' stress symptoms. 4) Coping with hardships though the years.

The interviews took place at the interviewee's home, after receiving their personal permission to be interviewed. At the beginning of each interview, the researcher clarified that the purpose of this study was to explore the personal experiences of being married to a former combat veteran with PTSD. In addition, complete anonymity was assured. It is important to note that most of the interviewees displayed special interest in the research and were happy to cooperate. All interviews were recorded and transcribed word for word, excluding any possibly identifying details. The length of each interview was between one to two hours. The total number of interviews took about two years to complete.

\section{Analysis}

\section{The Process of Realizing the Problem}

About 2/3 of the wives reported that for a long time (in a few cases up to several years) they did not know what the problem was with their husbands and had no idea that it was connected to his military experience. Those few wives, who knew from the beginning, got the information from an official institution like the hospital where their husbands had been hospitalized. What made the process longer and more complicated was the fact that more than half of the husbands suffered from delayed combat reaction that later turned into PTSD. In other words, the disorder did not appear in proximity to an identified experience (e.g., such as participating in a war) but months or even years after the husband's traumatic experience occurred. Sometimes the disorder started directly after an identified experience (e.g., reserve duty) and at other times, it developed gradually. These conditions make it very difficult for most wives to understand the causes and nature of their husbands' problems. The following are examples of the wives' reaction to the general question "how did you learn about your husband's problem?”.

"My husband fought in the 1973 war as a platoon commander $\cdots$ The outbreak started in $1988 \cdots$ He was on reserve duty and they had a simulation of war with casualties and how to bury soldiers $\cdots$ Then he came home and tried to stay next to me all the time $\cdots$ Later he started to cry and told me that on the way home he did not remember the way and did not understand where he was $\cdots$ Then he asked me to take him to a psychiatrist".

"I learned that my husband has combat reaction only after our first son was born $\cdots$ I understood that something was wrong ... He had many outbursts of anger".

It seems that not only had most of the wives lived with their PTSD husbands for a long time before they were officially diagnosed, but even when the diagnosis was made, wives receivedal most no information about the problem and got little if any information from the relevant authorities. In some cases, this process took up to ten years. Some of the wives described how little they understood about their husband's problem. Lack of information and/or understanding of the problem are more salient among wives whose husbands' combat reaction started after the 1973 war. The following are examples of the long process of recognition:

"Since 1974 I have known that he has combat reaction, but I did not know that combat reaction means nightmares and not sleeping well at night. No one approached me $\cdots$ the doctor asked me not to push him by asking for sexual relations $\cdots$ That was the only thing (the doctor told me)".

One wife related that her husband had kept his experience and many of his symptoms a secret for many years and she never thought that his problems had anything to do with trau- 
matic combat experience:

"It was about seven years ago, I had a serious operation and he was afraid that he was going to lose me and only then he told us everything. He kept it inside for many years '. I don't know how he had so much strength (to keep it as a secret) for such a long time ...”.

Some of the wives reported temporary relief after their husbands were officially diagnosed as suffering from PTSD. For the first time they received some understanding of his strange behavior and problems. For those wives it was some kind of an official affirmation that their husband was sick and should not be blamed for his behavior:

"I felt relief that there was a name for the problem. I felt like I was breaking down from something. Maybe I was not necessary, I don't know ... Instead of being happy, I cried”.

Overall, it seems that, for most wives, realizing and understanding that their husband had a PTSD syndrome took long time. Moreover, in most cases, the wives hoped and expected that things would get better sometime in the future. It took them many years to accept and internalize that their husband's case was chronic, with ups and downs which they had to live with in the long run. In most cases, it was a very difficult and painful process and in some cases continues in the present.

\section{Effects of the Husband's PTSD on Family Life}

Daily functioning. Beyond the differences between the families, all of the wives described many negative effects of their husband's situation on daily family functioning. In most cases, the wives described their husband as handicapped and as unable to carry out small tasks that are usually associated with normal family functioning: cleaning, taking care of the children, shopping, and the like. All of the wives were very frustrated, yet they were aware of their husbands' low ability to take part in daily family life. None of the wives blamed her husband for his situation but all of them sounded desperately pessimistic for any possible future change of the situation. For example:

"I think that my husband did not meet the children's teachers. I sent them to school, I did everything ‥ I am the only one who cleans ... Most times I cook even though he is a great cook ...”.

There seems to be great similarity among the wives when describing their husbands' low level of daily family functioning and lack of or little initiative: The husband waits for instructions about what to do. The main theme raised by the wives is the fact that almost all of the responsibility for daily family life rests on their shoulders.

Economic situation. About eight wives described economic deterioration due to their husband's situation. In some of the cases, their standard of living decreased dramatically when the family had to live on pensions from national insurance only. For example:

"When he stopped working, our economic situation deteriorated and I had to work full time in one place and at another half time job in another place $\cdots$ There were times when we really had nothing to eat; simply there was nothing to eat at home."

"We were in an excellent [financial] situation and all of a sudden boom! When my parents understood that we didn't have money they brought us food, took the girls shopping and this is what saved me."

In some cases the husbands' PTSD, whether it had started at once, or through a long process, caused him to quit his job (or to be fired) while at the same time, the family had great expenses for doctors, lawyers and medicine. As a result, most families became financially hard-pressed and this made the already complicated situation much worse. Some of the wives said that without the children to care for, they would not have had the ability or motivation to continue the struggle.

\section{The Couple-Hood Realm}

The "present-absent" husband. One of the most prominent findings in the women's stories relates to couple-hood and a familial reality in which the husband is "absent-present”. Physically the husband lives and is present in family life, although not actively. His figure exists. However, sometimes his emotional state causes him to detach himself from reality, as if he does not feel or respond to those around him and/or his environment. This gives rise to the impossible disparity between his apparent and visible figure, seemingly alive, and his conduct, lacking depth and content, the image of someone who is dying.

The language and the words these women choose to depict this condition, as well as their tones of voice, varied among wives and sharpened the differences in the way in which each woman tells her story. Nevertheless, the experiences and feelings are common and appear to express the same emotions. For example:

"He is living-dead. Sometimes he says things like that he would rather be dead, at least he would not suffer and would not be a burden upon his family. Of course, this is the last thing I would want to happen, and I'm most happy that he's with us, but I wouldn't lie if I said that there were a few times, during severe crises, that I thought that, in any case, he is like dead, like some ghost in the house. Then '- maybe it would be better to know that he is dead and that's it, and not to cope with this gap between having him physically, and nothing inside."

Social life and leisure time. Most wives reported that due to their husband's condition they have a very limited social life. It seems that the wives' limited social life takes place without the husband and includes friends and their close family. Furthermore, they report very limited family leisure time due to the husband's difficulties in going away from home and enjoying almost any leisure activity. For example:

"There is no social life at all. Since it happened, we have done nothing, no vacation. Once we went to a hotel a minute from home. He came because his psychiatrist asked him to get out of the house, for me … I have gone out by myself in the last four years. Before that, I was very afraid to leave him alone at home ‥ I go out with friends ‥ I go abroad as a tourist with friends."

Couple intimacy. Most wives reported very limited intimate relations and the majority of them said that they had often considered leaving their husbands and starting a new life. The main reason for staying with the husband was the fear that he would not survive the separation. It seems clear that the husbands' PTSD affects the couple's intimate relations significantly and negatively. For example:

"We haven't been intimate for the last couple of years. We have not had sex for many years. When I asked him why he replied that my body disgusts him. He says that I disturb his sleep ...”.

\section{Wives' Secondary Traumatization}

The most common reports regarding secondary traumatiza- 
tion are anxieties of all kinds and other symptoms also characterizing the husbands': general anxiety, phobias, sleep problems and bad dreams, guilt feelings and hyper-arousal. In addition, it is possible to identify fear of the future, possibly due to fear stemming from the realization that reality is not going to change, as well as the actual fear of the trauma being transmitted to the children. Their stories reveal that the trauma experiences sometimes cause them to dysfunction, to freeze, to dissociate from reality and to "get stuck". For example:

"I don't have nightmares, I have guilt feelings and pain as though it is me who went through the experience. Maybe it is because I identify with him ...”

"I have anxieties. There are times that I wake up with anxiety and feel that I am choking ... I could not get to sleep, I had real anxiety."

Overall, it seems that the wives did not talk much about their secondary traumatization symptoms. When asked directly, they described these briefly, as though this was not a central matter compared to issues such as their family life. Furthermore, almost none of the wives mentioned feeling depressed and some of them explained that they do not let these feeling gain controls.

\section{Coping with Difficulties along the Years}

Most of the women mention three prominent domains as assisting them to cope with hardships through the years. The first is the emotional relations that preceded the traumatic event, as fortifying their commitment to their partners: the love that was and still exists and the sense that this is what marriage was designated for-the difficult times the couple has to undergo and when needed to help each other. For example:

"We have very great love and a true friendship. When you see the closest person in the world suffering and falling apart, you only want to help him. At least for me it's like that. I will fight for my family with all of my strength $\cdots$ There are so many things to cope with ...”

The second domain is the partners' reactions - the recognition, the embrace and the gratitude all constitute the oil that maintains the fire of devotion, bound in sacrifice. This domain also includes the women's spiritual beliefs.

"... so what helped me is myself. You realize that there are things that you have to do in the universe, that you have a duty. I'm not talking about raising the kids; there's something that my soul has to cope with and this will lead me to a better place."

The third domain refers to the children. The interviewees mention that the children are the fruit of marriage. More than any other familial frame work, they are a strengthening factor and provide compensating qualities like humor, optimism, and a positive sense of future.

"What are the sources of strength? I don't know '. Look, I say to myself, ok I'm carrying this, I'm a strong person. I have my daughter which is this wish to carry on and not to fall and not to crash and to give her, at least on my part, a happy place in which to grow up, an optimistic and good place, good experiences ...”

\section{Discussion}

The main goal of the current study was to learn from wives of former combat veterans with chronic PTSD about their family life. The following questions guided the current study: what was the process of learning about the husband post trauma; how the husbands' situation affects different aspects of family life; what secondary traumatization symptoms characterized the wives, and what helps them to cope with this long-term challenging situation.

In most cases, the wives in this study indicated that for a long time they did not understand the changes in their husband's behavior and had no idea that these were somehow related to his army experience. Most studies that examine veterans with PTSD and the effects on the family (e.g., Ein-Dor et al., 2010; Gold et al., 2007) have not examined this period of disillusionment, or recognition. Our study suggest that this stage, which might take many months (sometime even years) is characterized by lack of understanding and information, confusions, shame and efforts to hide the husband's situation from close family members. Some of the wives describe this stage retrospectively as the worse period, since their husband experienced the traumatic event. The most common response regarding this stage was total misunderstanding of what the causes of their husbands' unusual behavior were and how to explain their deteriorating condition.

The wives describe this first stage as characterized by lack of communication and feelings of gradually detaching from their husband. This description is compatible with former studies (Solomon et al., 1987; Waysman \& Mikukulincer, 1990) indicating low levels of expressiveness and cohesion, as well as high levels of conflict in veterans' families, associated with PTSD diagnosis among CSR veterans. However, since few studies have explored the period from the potential traumatic event until the formal diagnosis of PTSD, further studies are required to widen our understanding regarding this stage. This could grant practitioners and professionals adequate knowledge about transmitting information about the PTSD diagnosis to families.

The main issue explored in our study was the effects of the husband's situation on his wife and family. Our results suggest highly negative effects on family life. The wives describe in detail the tremendous negative effects on the following aspects of their lives: daily functioning, economic difficulties, lack of couple intimacy, poor parenthood and very little social life and leisure time. These results corroborate other studies, indicating the negative effects of the husbands' traumaon the entire family (Ben Arzi, Solomon, \& Dekel, 2000; Bramsen, Van der Ploeg, \& Twisk, 2002; Galovski \& Lyons, 2004; Ein-Dor, Doron, Mikulincer, Solomon, \& Shaver, 2010; Ray \& Nanstone, 2009; Renshaw et al., 2011; Solomon et al., 2011). However, these studies mainly focused on levels of various symptoms compared to control groups. Unlike these studies, the current study focused on the subjective perspective of the wives describing processes within their family life.

The authors think that the most important and genuine issue revealed in this study is the "present-absent" husband phenomenon. The wives described their husbands as physically present, yet many times dissociated from family life. Some of the wives used metaphors to name this situation such as "living dead". These "present-absent" situations leave the wife alone, many times not only lacking of support and someone to lean on, but also with a constant demand to take care of and worry about the helpless husband. In the worst case, they even talked about constant worries when leaving home that their husband might harm himself. It seems to us that this ongoing situation is one of the most difficult for the wives in our study, and this is consis- 
tent with former researchers who point to the numbness/ avoidance symptoms of PTSD as the most harmful to the family (Evans et al., 2003; Hendrix, Erdmann, \& Briggs, 1998; Riggs et al., 1998; Taft, Schumm, Panuzio, \& Proctor, 2008).

Furthermore, the ambiguity and disorganization in the women's lives is enhanced by the discrepancy between the husband's mental state and his physical condition. This discrepancy finds expression in dissociation and detachment from reality, which certainly bring about a disrupted perception of reality. This notion is compatible with Pennebaker and Seagal's (1999) assertion that trauma, by definition, breaks the sense of continuity, of flow and consecutiveness which is the basis for a sense of meaning. Thus, it disrupts the perception of reality. Overall, it seems that the use of metaphors and expressions such as "dead-live”, "present-absent”, "empty within”, "wall” and the like, assist the women in describing the intensity of their feelings and emotions in the presence of such a discrepancy.

Finally, all the wives we interviewed for the current study stayed with their husbands regardless of the very difficult life they have experienced, demonstrating rather high levels of commitment to the relationship. This finding is compatible with reports by Dekel et al. (2005) and Dekel (2007) that wives of combat stress reaction veterans displayed moral and conscientious commitment to their partners. It is plausible that the feelings of commitment, devotion and care for the children together with the idea that the husband might not survive separation has served as the main bond holding the couple together and has helped the wives to carry on. Moreover, the women in Dekel et al.'s (2005) research reported some positive aspects of their marital relationship, addressing the partners as "empowering" in some way, which may also account for the effect of staying in the relationship. To the best of our knowledge, this issue has hardly been studied.

\section{Limitations of the Study}

The present research has some limitations, as follows: 1) The small number of interviewees requires caution in generalizing our findings to the general population of Israeli wives of veterans with PTSD. However, one should keep in mind that qualitative research, like ours; aims to gather an in-depth understanding regarding a wife's life with a former combat veteran husband who suffers from chronic PTSD. 2) It is difficult to compare the current study with other studies regarding wives of veterans with PTSD, which used mainly quantitative methodology. 3) Caution should be applied due to the fact that wives of veterans with PTSD who have recovered to a considerable degree were not part of the current study, yet their stories merit inquiry and comparison to the current study group.

\section{Conclusions and Suggestions for Future Studies}

The main conclusion seems to be the tremendous aversive effects of the veterans with chronic PTSD on their families for many years, or even for their entire lives, since the husband's injury. The family lives of these people can be described as a constant struggle for survival on the one hand, yet on the other hand, the studied wives display high levels of commitment to their "wounded" husbands. The women who participated in the current study offer a rare and genuine glimpse into their narratives. The women are diverse in their degree of clarity, con- solidation and organization they grant to their stories; nevertheless, they reveal common themes of coping with their longterm difficult situation.

Overall, a practical conclusion seems to be that wives of former combat veterans with PTSD might well benefit from early family consultation (preferably given by specialized psychologists) to accompany, guide and support these families in their long-term tough struggle to keep their heads above water.

It is highly recommend that further studies based on interviews with wives of veterans with PTSD should take place in other cultures and include wives whose husband have recovered considerably from their trauma.

\section{REFERENCES}

American Psychiatric Association (2000). Diagnostic and statistical manual of mental disorders (4th ed.). Washington DC: American Psychiatric Association.

Andrews, B., Brewin, C. R., Stewart, L., Philpott, R., \& Hejdenberg, J. (2009). Comparison of immediate-onset and delayed-onse posttraumatic stress disorder in military veterans. Journal of Abnomal Psychology, 1118, 767-777. doi:10.1037/a0017203

Becvar, D. (2013). Handbook of family resilience. New York: Springer Science + Business Media. doi:10.1007/978-1-4614-3917-2

Ben Arzi, N., Solomon, Z., \& Dekel, R. (2000). Secondary traumatization among wives of PTSD and post-concussion casualties: Distress, caregiver burden and psychological separation. Brain Injury, 14, 725-736. doi:10.1080/026990500413759

Benyamini, Y., Ein-Dor, T., Ginzburg, K., \& Solomon, Z. (2009). Trajectories of self-rated health among veterans: A latent growth curve analysis of the impact of posttraumatic symptoms. Psychosomatic Medicine, 71, 345-352. doi:10.1097/PSY.0b013e31819ccd10

Benyamini, Y., \& Solomon, Z. (2005). Combat stress reaction, posttraumatic stress disorder, cumulative life stress, and physical heath among Israeli veterans twenty years after exposure to combat. Social Science \& Medicine, 61, 1267-1277. doi:10.1016/j.socscimed.2005.01.023

Berger, R., \& Weiss, T. (2009). The posttraumatic growth model: An expansion to the family system. Traumatology, 15, 63-74. doi:10.1177/1534765608323499

Black, K., \& Lobo, M. (2008).A conceptual review of family resilience factors. Journal of Family Nursing, 14, 33-55. doi:10.1177/1074840707312237

Bonanno, G. A. (2004). Loss, trauma, and human resiliece: Have we underestimated the human capacity to thrive after extremely aversive events? American Psychologist, 59, 20-28. doi:10.1037/0003-066X.59.1.20

Bramsen, I., Van der Ploeg, H. M., \& Twisk, J. W. R (2002). Secondary traumatization in Dutch couples of World War II Survivors. Journal of Counseling and Clinical Psychology, 70, 241-245. doi:10.1037/0022-006X.70.1.241

Bronfenbrenner, U. (2005). Child care in the Anglo-Saxon mode. In U. Bronfenbrenner (Ed.), Makinghuman being human: Bioecological perspectives on human development. (pp. 274-282). Thousand Oaks, CA: Sage.

Butcher, J. N., Mineka, S., \& Hooley, J. M. (2010). Abnormal psychology (14 ed.). New York: Allyn \& Bacon.

Cardena, E., \& Carlson, E. (2011). Acute stress disorder revisited. Annual Review of Clinical Psychology, 7, 245-267. doi:10.1146/annurev-clinpsy-032210-104502

Cohen, E., Zerach, G., \& Solomon, Z. (2011).The implication of combat-induced stress reaction, PTSD, and attachment in parenting among war veterans. Journal of Family Psychology, 25, 688-698. doi:10.1037/a0024065

Dekel, R. (2007). Posttraumatic distress and growth among wives of prisoners of war: The contribution of husbands' posttraumatic stress disorder and wives' own attachment. American Journal of Orthopsychiatry, 77, 419-426. doi:10.1037/0002-9432.77.3.419 
Dekel, R., Goldblatt, H., Keidar, M., Solomon, Z., \& Polliack, M. (2005). Being a wife of a veteran with posttraumatic stress disorder. Family Reltions, 54, 24-36. doi:10.1111/j.0197-6664.2005.00003.x

Dekel, R., \& Solomon, Z. (2006). Secondary traumatization among wives of Israeli POWs: The role of POWs' distress. Social Psychiatry \& Psychiatric Epidemiology, 41, 27-33. doi:10.1007/s00127-005-0002-6

Dirkzwager, A. J. E., Bramsen, I., Ader, H., \& van der Ploge, H. M. (2005). Secondary traumatization in partners and parents of Dutch peacekeeping soldiers. Journal of family Psychology, 19, 217-226. doi:10.1037/0893-3200.19.2.217

Ein-Dor, T., Doron, G., Mikulincer, M., Solomon, Z., \& Shaver, P. R. (2010). Together in pain: Attachment-related dyadic processes and posttraumatic stress disorder. Journal of Counseling Psychology, 57, 317-327. doi:10.1037/a0019500

Evans, L., McHugh, T., Hopwood, M., \& Watt, C. (2003). Chronic posttraumatic stress disorder and family functioning of Vietnam veterans and their partners. Australian and New Zealand Journal of Psychiatry, 37, 765-772. doi:10.1080/j.1440-1614.2003.01267.x

Everson, R. B., \& Figley, C. R. (2011). The long way home: The aftermath of war for service members and their families. In R. B. Everson, \& C. R. Figley. Families under fire: Systemic therapy with military families (pp. 277-286). New York: Routledge/Taylor \& Francis Group.

Figley, C. R. (1983). Catastrophes: An overview of family reactions. In C. R. Figley \& H. I. McCubbin (Eds.), Stress and the Family, Vol. II: Coping with catastrophe (pp. 3-20). New York: Brunner/Mazel.

Galovski, T., \& Lyons, J. A. (2004). Psychological sequelae of combat violence: A review of the impact of PTSD on the veteran's family and possible interventions. Aggression and Violent Behavior, 9, 477501. doi:10.1016/S1359-1789(03)00045-4

Gold, J. I., Taft, C. T., Keehn, M. G., King, D. W., King, L. A., \& Samper, R. E. (2007). PTSD symptom severity and family adjustment among female Vietnam veterans. Military Psychology, 19, 7181. doi:10.1080/08995600701323368

Hendrix, C. C., Erdmann, M. A., \& Briggs, K. (1998). Impact of Vietnam veterans' arousal and avoidance on spouses' perceptions of family life. American Journal of Family Therapy, 26, 115-128. doi:10.1080/01926189808251092

Hobfoll, S. E. (2001). The influence of culture, community, and the nested-self in the stress process: Advancing conservation of resources theory. Applied Psychology: An International Review, 50, 337-421. doi:10.1111/1464-0597.00062

Jones, D. K., Evenson, K. R., Rodriguez, D. A., \& Aytur, S. A. (2010). Addressing pedestrian safety: A content analysis of pedestrian master plans in North Carolina. Traffic Injury Prevention, 11, 57-65. doi:10.1080/15389580903434199

Krippendorf, K. (1980). Content analysis: An introduction to its methodology. Beverly Hills, CA: Sage.

Magruder, K. M., \& Yeager, D. E. (2009).The prevalence of PTSD across war eras and the effect of deployment on PTSD: A systematic review and meta-analysis. Psychiatric Annals, 39, 778-788. doi:10.3928/00485713-20090728-04

Marshall, M. G., \& Cole, B. R. (2009). Global report 2009: Conflict, governance, and state fragility. Fairfax, VA: George Mason University, Center for Systemic Peace and Center for Global Policy.

McCubbin, H. I., Boss, P., Wilson, L., \& Lester, G. (1980). Developing family invulnerability to stress: Coping patterns and strategies wives employ in managing family separations. In J. Trost (Ed.), The family in change (pp. 379-405). Visteras: International Library.

McCubbin, H. I., \& Patterson, J. (1982). Self Reliance Index (SRI). In H. I. McCubbin, A. I. Thompson, \& M. A. McCubbin, Family assessment: Resiliency coping and Adaptation-Inventories for research and practice (pp. 625-637). Madison: University of Wisconsin System.

McCubbin, H. I., Thompson, E. A., Thompson, A. I., \& Fromer, J. E.
(1998). Stress, coping, and health in families: Sense of coherence and resiliency. Thousand Oaks, CA: Sage Publications.

McFarlane, A. C. (2010). The long-term costs of traumatic stress: Intertwined physical and psychological consequences. World Psychiatry, 9, 3-10.

Pennebaker, J. W., \& Seagal, J. D. (1999). Forming a story: The health benefits of narrative. Journal of Clinical Psychology, 55, 1243-1254. doi:10.1002/(SICI)1097-4679(199910)55:10<1243::AID-JCLP6>3.0 . $\mathrm{CO} ; 2-\mathrm{N}$

Ray, S., \& Nanstone, M. (2009). The impact of PTSD on veterans' family relationships: An interpretative phenomenological inquiry. International Journal of Nursing Studies, 46, 838-847.

doi:10.1016/j.ijnurstu.2009.01.002

Renshaw, K. D., \& Campbell, S. B. (2011).Combat veterans’ symptoms of PTSD and partners' distress: The role of partners' perceptions of veterans' deployment experiences. Journal of Family Psychology, 10, 953-962. doi:10.1037/a0025871

Renshaw, K. D., Blais, R. K., \& Caska, C. M. (2011). Distress in spouses of combat veterans: The importance of interpersonally based cognitions and behaviors. In S. MacDermid Wadsworth, \& D. Riggs (Eds.), Risk and resilience in US military families (pp. 69-84). New York: Springer. doi:10.1007/978-1-4419-7064-0_4

Renshaw, K. D., Rhoades, G. K., Allen, E. S., Blais, R. K., Markman, H. J., \& Stanley, S. M., (2011). Distress in spouses of service members with symptoms of combat-related PTSD: Secondary traumatic stress or general psychological distress. Journal of Family Psychology, 25, 461-469. doi:10.1037/a0023994

Riggs, D. S., Byrne, C. A., Weathers, F. W., \& Litz, B. T. (1998). The quality of the intimate relationships of male Vietnam veterans: Problems associated with posttraumatic stress disorder. Journal of Traumatic Stress, 11, 87-101. doi:10.1023/A:1024409200155

Smid, G. E., Mooren, T. T., van der Mast, R. C., Gersons, B. P., \& Kleber, R. (2009). Delayed posttraumatic stress disorder: Systematic review, meta-analysis, and met-regressions analysis of prospective studies. The Journal of Clinical Psychiatry, 70, 1572-1582. doi:10.4088/JCP.08r04484

Solomon, Z., Debby-Aharon, S., Zerach, G., \& Horesh, D. (2011). Marital adjustment, parental functioning, and emotional shring in war veterans. Journal of Family Issues, 32, 127-147. doi:10.1177/0192513X10379203

Solomon, Z., Horesh, D., \& Ein-Dor, T. (2009). The longitudinal course of posttraumatic stress disorder symptom clusters among war veterans. Journal of Clinical Psychiatry, 70, 837-840. doi:10.4088/JCP.08m04347

Taft, C. T., Schumm, J. A., Panuzio, J., \& Proctor, S. P. (2008). An examination of family adjustment among operation desert storm veterans. Journal of Consulting and Clinical Psychology, 76, 648-656. doi:10.1037/a0012576

Umbrasas, K. (2010). Keeping the diagnostic lens polished: Psychological reactions to stress. Annals of the American Psychotherapy Assn, 13, 68-69.

Wadsworth, S. M. (2010). Family risk and resilience in the context of war and terrorism. Journal of Marriage and Family, 72, 537-556. doi:10.1111/j.1741-3737.2010.00717.x

Walsh, F. (2011). Family resilience: A collaborative approach in response to stressful life events. In S. M. Southwick, D. Charney, \& M. J. Friedman (Eds.). Resilience and mental health: Challenges across the lifespan (pp. 149-161). Cambridge: Cambridge University Press.

Waysman, M., Mikulincer, M., Solomon, Z., \& Weisenberg, M. (1993). Secondary traumatization among wives of posttraumatic combat veteran: A family typology. Journal of Family Psychology, 7, 104-118. doi:10.1037/0893-3200.7.1.104

Wizelman, L. (2011). When the war never ends: The voices of military members with PTSD and their families. Lanham, MD: Rowman \& Littlefield Publisher. 